\title{
МИСТИКА И ИСТИНА ГИПЕРБОЛИЧЕСКОГО ЗАКОНА
}

\section{ВАЛЕНТИН КОНОНОВ}

\begin{abstract}
Анализ результатов, полученных классиками закона гиперболического роста численности мирового населения, показывает, что они основаны почти исключительно на оченках за 1650-1970 г2. В другие периоды динамика численности населения подчинялась другим законам, причем этапь роста, отождествимые с движением по аттракторам, сменялись этапами стагнации, которые можно рассматривать как точки бифуркачии.
\end{abstract}

Требует переосмысления также и распространенное понимание гиперболического роста как следствия технологического развития. Большинство парадоксов закона находят разрешение, если в качестве движущей силы, определяющей развитие человечества, рассматривать информационные прочессы.

Ключевые слова: численность населения, гиперболический рост, аттрактор, точка бифуркачии, демографический императив, информационный императив.

В 1960 г. работавший в США австрийский физик Хайнц фон Фёрстер с соавторами опубликовал статью с отдающим мистикой названием «Судный День: пятница, 13 ноября, 2026 год нашей эры» [Foerster, Mora, Amiot 1960], в которой обосновал закон гиперболического роста численности населения Земли (рисунок 1). С помощью метода наименьших квадратов авторы определили, что с начала нашей эры численность населения планеты изменялась в соответствии с удивительно простой формулой:

$$
\mathrm{N}_{\mathrm{t}}=\frac{\mathrm{C}}{\left(\mathrm{t}_{0}-\mathrm{t}\right)^{\mathrm{n}}},
$$

где $N_{t}$ - численность населения в году $t ; t_{0}=2027 \pm 5\left(\right.$ лет); $C=(179 \pm 0,14) * 10^{9}$ (человек*лет); $n=0,99 \pm 0,009$.

Параметр $t_{0}$ определяет точку сингулярности: при $t=t_{0}$ выражение в правой части теряет смысл, что и было интерпретировано авторами как судный день. Разумеется, интерпретировано иронически (13 ноября 2026 г. исполнится 115 лет со дня рождения Фёрстера), никто не сомневался в том, что задолго до достижения указанной даты произойдут изменения в темпах роста населения и ничего экстремального не произойдет. И действительно, ускорение роста численности населения прекратилось уже в семидесятые годы. Начиная с 1990-х годов уменьшается и средний ежегодный прирост [UN 2013].

ВАЛЕНТИН ГЕОРГИЕВИЧ КОНОНОВ, НЕЗАВИСИМЫЙ ЭКСПЕРТ. РОССИЯ.

E-mail: v_kononov@mail.ru

СТАТЬЯ ПОСТУПИЛА В РЕДАКЦИЮ В ДЕКАБРЕ 2014 Г. 


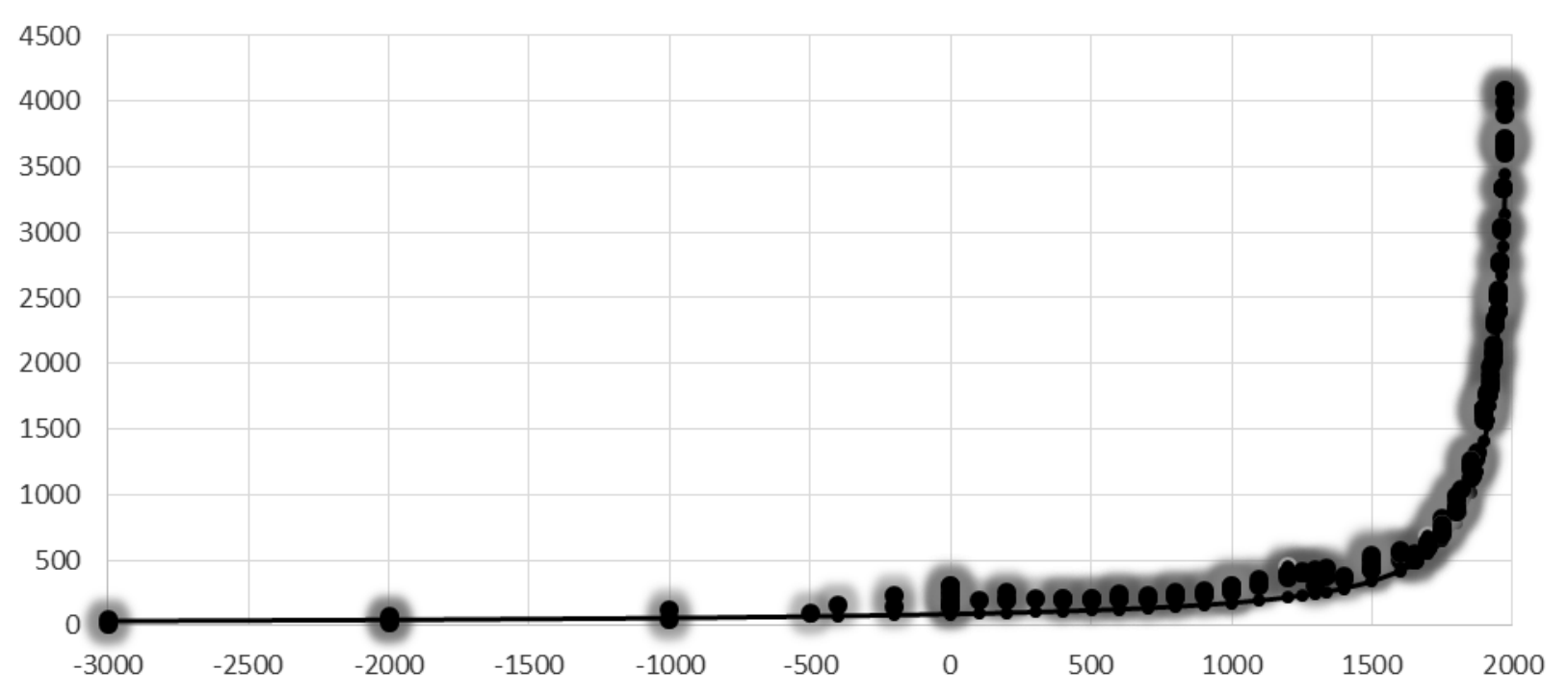

Рисунок 1. Гиперболический закон роста численности населения по Фёрстеру, млн человек

Но мистика гиперболического закона этим не заканчивается, а, можно сказать, только начинается. С.В. Цирель [2015] в своём выступлении на конференции в Институте демографии Высшей школы экономики выделил три парадокса закона:

1. Возможность описания столь важного параметра исторического процесса, как рост численности населения Земли, единой и очень простой формулой, несмотря на всю сложность истории человечества.

2. Вся человеческая история запрограммирована, год $\mathrm{t}_{0}=2025 \pm 25$ как дата конца света (или более скромно - как примерное время изменения закона роста народонаселения) был предопределён задолго до Рождества Христова (по самым щедрым оценкам - ещё при появлении первых гоминид).

3. Дифференциальная форма закона гиперболического роста:

$$
\frac{\mathrm{dN}}{\mathrm{dt}}=\frac{\mathrm{C}}{\left(\mathrm{t}_{0}-\mathrm{t}\right)^{2}}=\frac{\mathrm{N}^{2}}{\mathrm{C}}
$$

показывает, что рост числа людей на протяжении всей истории, в отличие от роста численности популяций животных и растений, подчинялся не линейной, а квадратичной зависимости от численности, и именно численности всего человечества.

Кроме того, докладчик назвал шесть парадоксов его основного объяснения, но об этом ниже. Однако и этот список далеко не полон. В 1975 г. немецкий астрофизик Себастьян фон Хорнер, также работавший в США, уточнил параметры гиперболического закона, использовав оценки численности населения планеты за различные даты, сделанные после публикации статьи Фёрстера (и в значительной степени благодаря ей) [Hoerner 1975]. Гипербола Хорнера имеет следующие параметры: $t_{0}=2025, C=200 * 10^{9}, n=1$.

Эти значения выглядят как сильно округлённые, однако метод наименьших квадратов, применённый к имеющимся оценкам за 1650-1970 гг., с большой точностью даёт именно их! Особенно поразительно то, что значения $t_{0}$ ип почти совпадают с полученными Фёрстером по небольшому числу неточных оценок. Если бы из имевшихся у 
австрийского ученого оценок хотя бы одна(!) была достаточно точной, ему не удалось бы получить такого результата.

Увеличение значения параметра $C$ на $17 \%$ существенно приближает гиперболу в форме Хорнера к имеющимся оценкам за 1650-1970 гг. [US Census Bureau 2010; HYDE 2011; UN 2013]. Медианные значения оценок за все даты из этого интервала отклоняются от расчетных не более чем на 9\% (рисунок 2). Но все оценки за предыдущие два тысячелетия превосходят и эту гиперболу ([McEvedy, Jones 1978; Biraben 1980; UN 1999; HYDE 2011] и др.). С начала нашей эры до 1340 г., когда эпидемия чумы поразила всю Евразию, численность мирового населения превышала расчетную на 30-100\%. И даже после эпидемии, унёсшей жизни множества людей во всём мире, на протяжении примерно 300 лет сохранялось превышение на 15-20\% (имеются оценки лишь за 3 даты из этого интервала). В то же время оценки за даты до 500 г. до н.э. лежат в основном ниже гиперболы.

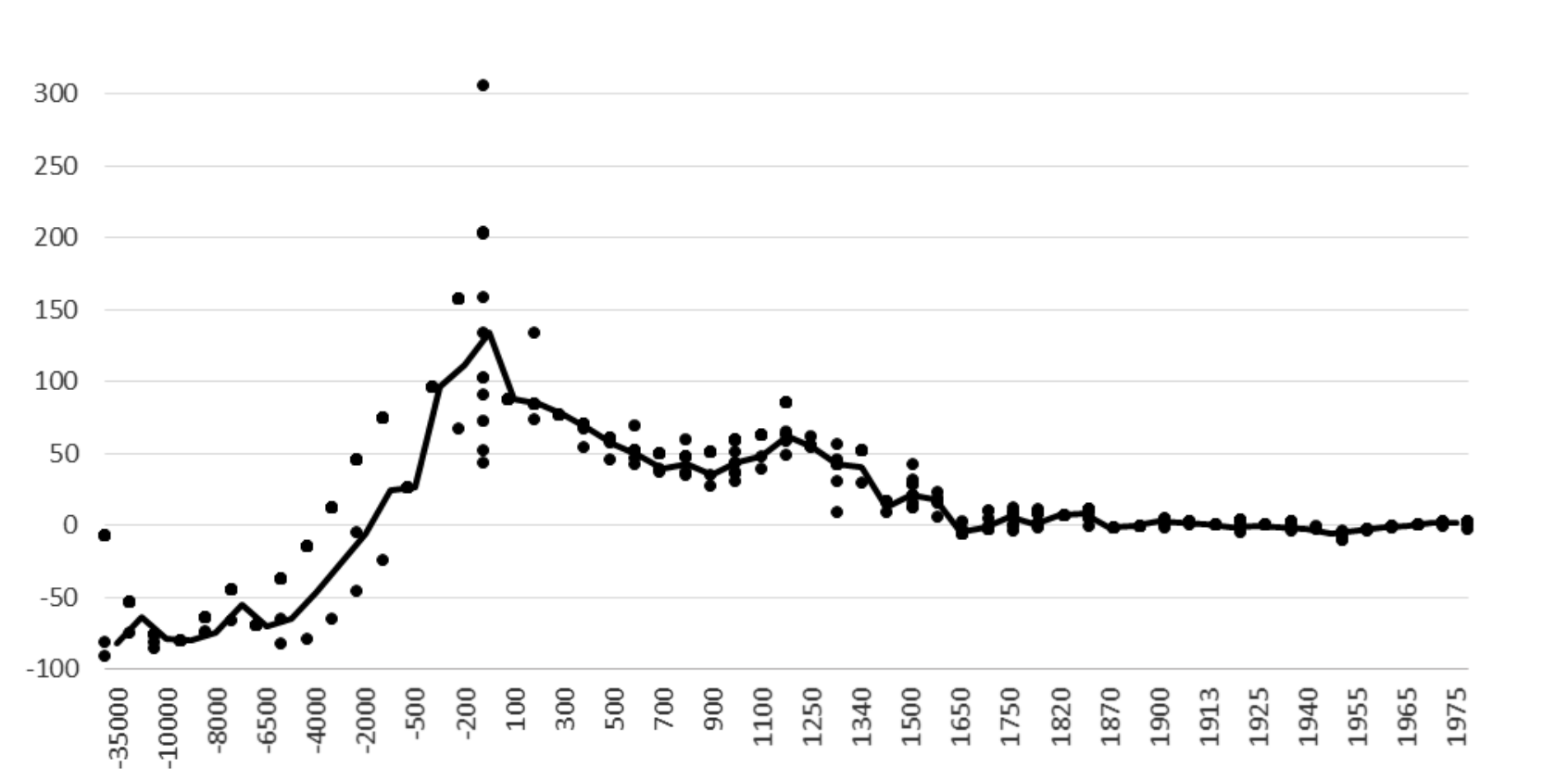

Рисунок 2. Отклонение оценок за различные даты от гиперболы Хорнера, \%

Однако, несмотря на это, Хорнер считал, что гиперболический закон в уточненной им форме действовал на всём протяжении существования человечества. Логика его рассуждений вполне понятна: с точки зрения астрофизика, занимавшегося проблемами внеземного разума, «небольшие» отклонения, имевшие место в истории Земли, не столь существенны в сравнении с общим процессом изменения численности человеческой популяции. А общий процесс, представленный в абсолютных цифрах, как мы видели на рисунке 1, замечательно соответствует гиперболической форме. Причём при продлении оси времени до любой даты до нашей эры видимое соответствие будет только возрастать, поскольку известные оценки лежат между 0 и расчетными величинами, а сами расчетные величины на таком графике неотличимы от нуля. 
С. П. Капица [1997] предложил модель роста численности населения, исключающую сингулярность: предположив, что степень знаменателя не может отличаться от единицы и добавив в дифференциальной форме закона:

$$
\frac{\mathrm{dN}}{\mathrm{dt}}=\frac{\mathrm{C}}{\left(\mathrm{t}_{0}-\mathrm{t}\right)^{2}}
$$

$\tau^{2}$ в знаменатель (здесь $\tau$ - «характерное время человека» порядка 40-50 лет), он получил для численности человечества формулу:

$$
N=\frac{C}{\tau} \operatorname{arcctg}\left(\frac{t_{1}-t}{\tau}\right) .
$$

В такой форме кривая практически совпадает с классической гиперболой до приближения к точке перегиба $t_{1}$, немного смещённой относительно точки сингулярности $t_{0}$ (в последней версии модели $t_{1}=1995$ г.). После этой точки рост продолжается неограниченно долго, но его скорость падает, сначала быстро, затем постепенно замедляясь. На начальном этапе развития человечества, по мнению Капицы, действовал линейный закон роста ${ }^{1}$, но 1,6 млн лет назад он сменился гиперболическим, причём константы $\tau$ и $K=\sqrt{\frac{c}{\tau}}$ никогда не менялись.

Логика Хорнера-Капицы популярна и сегодня, хотя имеются свидетельства [Коротаев 2006, Цирель 2008], что по крайней мере однажды, в конце первого тысячелетия до нашей эры, уже произошло изменение параметров закона развития человечества (что видно и на рисунке 2). Коротаев [2006] подробно проанализировал феномен отличия закона, действовавшего в интервале 40000-200 гг. до н.э., по его мнению, безусловно гиперболического, от закона, установившегося в дальнейшем. Он обнаружил, что в новое время заметно снизилась интенсивность роста и связанных с ним процессов, выраженная в относительных единицах. К примеру, отношение числа изобретений к численности населения в предыдущую эпоху было больше, чем в наше время.

Если бы гиперболический закон в неизменной форме был справедлив на всём протяжении существования человечества, то и определить его параметры можно было бы по любой выборке данных о численности человечества за различные даты. На рисунке 3 представлены графики изменения точки сингулярности, вычисленной по методу наименьших квадратов по различным наборам оценок. В зависимости от выбранного интервала оценок этот параметр (как, разумеется, и два других) изменяется в весьма широких пределах.

\footnotetext{
1 Чтобы определить время начала действия линейного закона, т.е. образования человечества, Капица сделал ошибочное предположение, будто скорость роста не может быть меньше одного человека за характерное время $\tau$. Судя по всему, рост численности отождествляется при этом с рождаемостью, что неверно, но никто, по-видимому, до сих пор не указал на эту ошибку, и ее периодически повторяют разные авторы.
} 


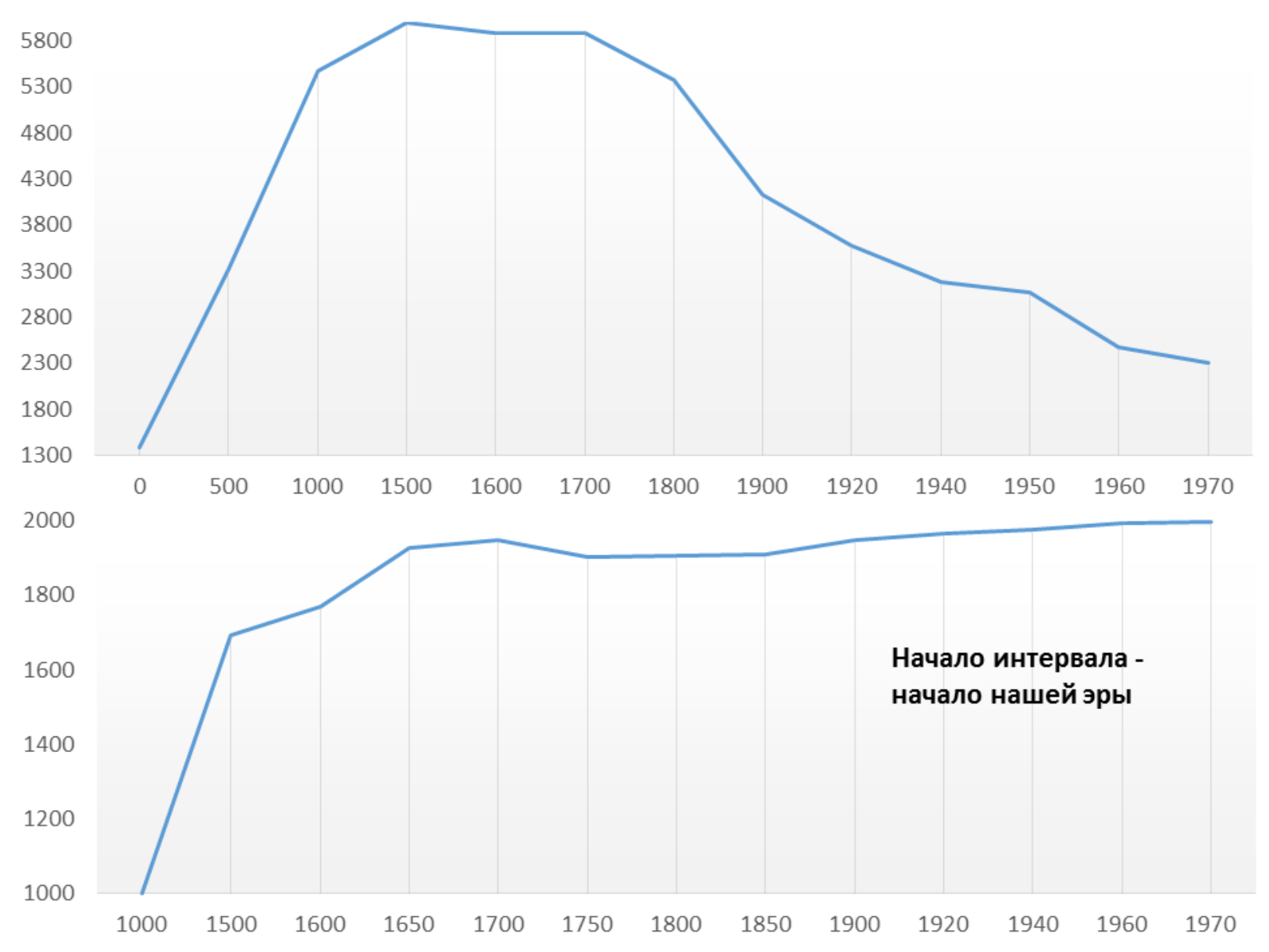

Рисунок 3. Изменение параметра to в зависимости от конца интервала учитываемых оценок

Таким образом, во втором парадоксе Циреля дата предопределения процесса оказывается не столь давней; по крайней мере, до Рождества Христова ничто не указывало на XXI век как век завершения действия закона.

А.В. Коротаевым, А.С. Малковым и Д.А. Халтуриной [2005b] была предложена модель роста численности в виде системы трёх уравнений²:

$$
\begin{aligned}
& \frac{d N}{d t}=a N S(1-L) \\
& \frac{d S}{d t}=b N S \\
& \frac{d L}{d t}=c S L(1-L)
\end{aligned}
$$

2 Е.Б. Постников [Postnikov 2015] свёл систему к одному дифференциальному уравнению, исключив переменные $L$ и $S: \frac{d N}{d t}=\left[a \mu N+b N^{2}+b N^{2} \sum_{n=1}^{\infty} \frac{\left(\lambda N^{\frac{c}{a}}\right)^{n}}{\left(1+n \frac{c}{a}\right)}\right]\left(1-\lambda N^{\frac{c}{a}}\right)$.

Возможность исключения параметров $L$ и $S$ из системы не означает, что рост численности населения с ними не связан. Напротив, она обусловлена однозначной взаимозависимостью между ними. 
Здесь $N$ - численность населения, $S$ - избыточный продукт, $L$ - относительный уровень грамотности (авторы [Коротаев и др. 2010] предлагают также рассматривать $L$ как один из параметров интегративной переменной - человеческого капитала).

В отличие от модели Капицы модель Коротаева-Малкова-Халтуриной достигает предельного значения $N=N_{\max }$ за конечное время. Можно провести аналогию между этой моделью и «логистической» моделью Ферхюльста:

$$
\frac{d N}{d t}=r N\left(1-\frac{N}{K}\right)
$$

Обе модели реализуются в виде S-образных кривых, т.е. имеют медленные участки в начале и конце развития. При этом одна, характерная для биоты, основана на экспоненте, а другая, специфично человеческая - на гиперболе. Обе описывают заполнение популяцией некоторого объёма, экологической ниши. Но в отличие от ёмкости ниши в биосфере $K$ предельная величина человеческой популяции $N_{\max }$ не связана с наличными ресурсами. В начальный момент развития ресурсов для такой численности населения абсолютно недостаточно.

В «гиперлогистической» модели Коротаева-Малкова-Халтуриной (5-7) имеется два «тормозящих» множителя: падающий уровень неграмотности $1-L$ определяет завершение роста, а величина избыточного продукта $S$ на душу населения замедляет рост на начальном этапе ( $S=T-m$, где $T$ - весь произведённый человечеством продукт на душу населения, $m$ - его необходимая часть). $S$ является прямым аналогом незаполненной части ниши $K-N$. Но для человечества эта величина со временем не убывает, а напротив, растёт. Смысл этого в том, что избыточный продукт направляется, в том числе, и на развитие науки, культуры, образования, и чем он больше, тем быстрее рост человечества.

Если на начальном участке у логистической кривой скорость относительного роста максимальна, то у «гиперлогистической» - минимальна. Однако следует обратить внимание, что нулевых значений $L$ и $S$ для старта «гиперлогистической» модели недостаточно. Поскольку в реальности изменения окружающей среды делают размер избыточного продукта величиной непостоянной, в этом нет ничего особенного человечество никогда не могло существовать, не имея хотя бы небольшого резерва.

В отличие от стандартного закона гиперболического роста «гиперлогистическая» модель (параметры подобраны методом наименьших квадратов) неплохо описывает изменение численности человечества в интервале 500-2000 г. н.э. (рисунок 4). 


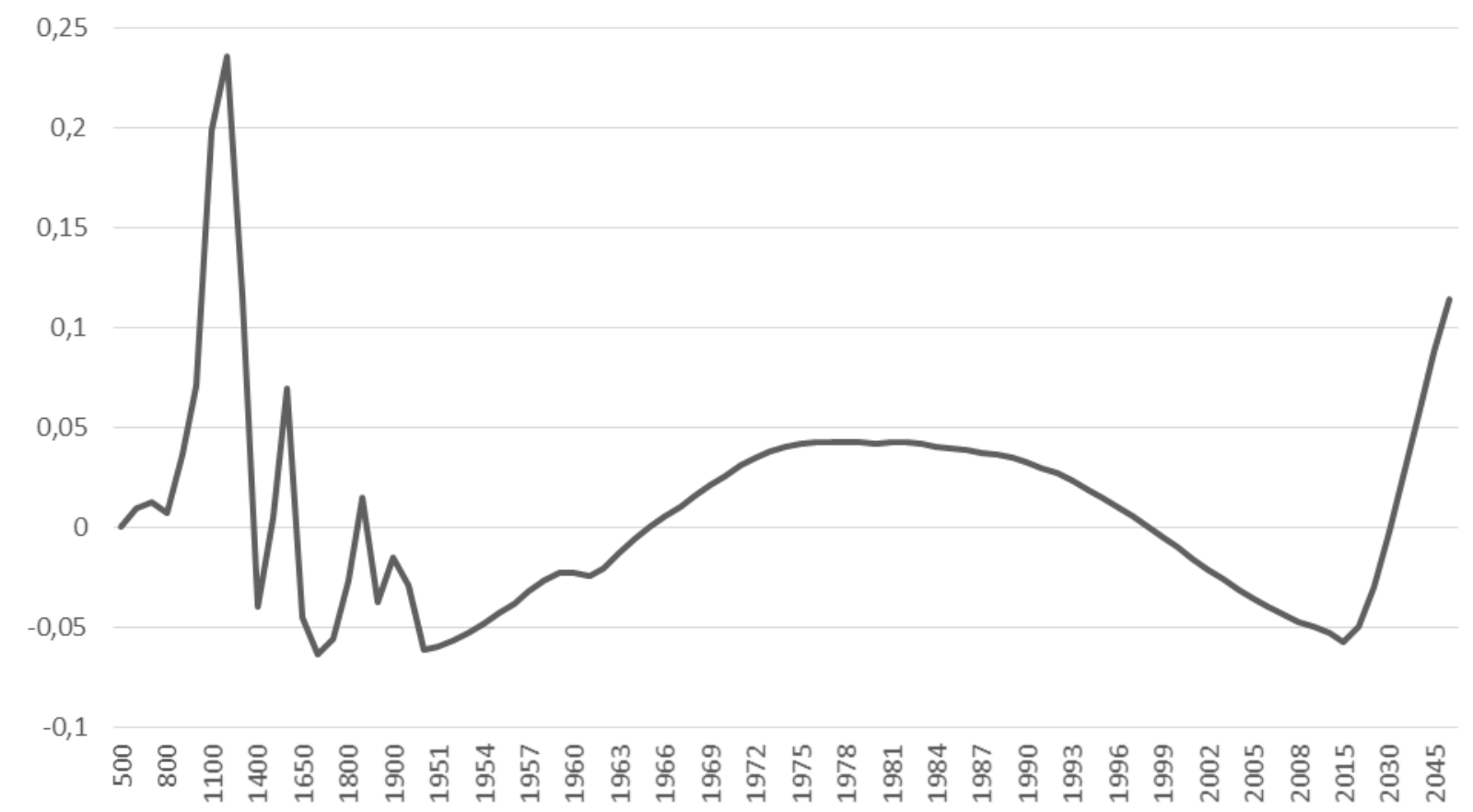

Рисунок 4. Отклонение оценок за даты с 500 по 2050 г. от «гиперлогистической» кривой $\left(R^{2}=0,9979\right)$

Более того, неожиданно хорошее совпадение с оценками Мак-Эведи и Джонса [McEvedy, Jones 1978] модель даёт и в интервале 5000 г. до н.э. - 500 г. н.э. ${ }^{3}$ Правда, этих оценок немного, но коэффициент корреляции между логарифмами теоретической кривой и имеющихся оценок здесь также выше, чем у гиперболического закона. Очередным парадоксом можно назвать достижение величиной $L$ уже к 200 г. н.э. уровня 1 в отсутствие высокого уровня грамотности и других параметров человеческого капитала.

Сопоставляя два интервала роста численности человечества (до и после начала нашей эры), следует также обратить внимание на то, что величины $L$ и $S$ в начале второго интервала неожиданно «обнулились», упали до минимального уровня, что, собственно, и позволило начать новый этап роста численности человечества. Возможно, это объясняется распадом науки и культуры в тогдашних гегемонах - Римской и Ханьской империях. Почти весь имевшийся к этому времени избыточный продукт $S$ был уничтожен или пущен на потребление, т.е. превратился в необходимый продукт $m$.

Как бы то ни было, уверенный рост численности населения перед началом и во втором тысячелетии нашей эры выглядит как движение по аттрактору. Напротив, в начале нашей эры рост численности населения был невелик или вообще отсутствовал. Если оценки численности населения в нулевом году лежат в диапазоне 150-330 млн человек, то для 500 г. н.э. приводятся оценки от 190 до 250 млн. На протяжении этих 500 лет интервалы

\footnotetext{
${ }^{3}$ Имеются противоречивые оценки численности населения в это время. Помимо наиболее полного ряда оценок, данного Мак-Эведи и Джонса, имеются ряд оценок Бирабена [Biraben 1980] и отдельные оценки других авторов. Все они более или менее соответствуют гиперболическому закону роста. Однако наиболее свежие данные нидерландских ученых [HYDE 2011] для этого периода идеально соответствуют экспоненте. Возможно, впрочем, что это связано со способом их получения.
} 
некоторого роста сменялись интервалами стагнации, а возможно и сокращения численности. Такую картину можно интерпретировать как переход человечества в начале нашей эры в зону бифуркаций.

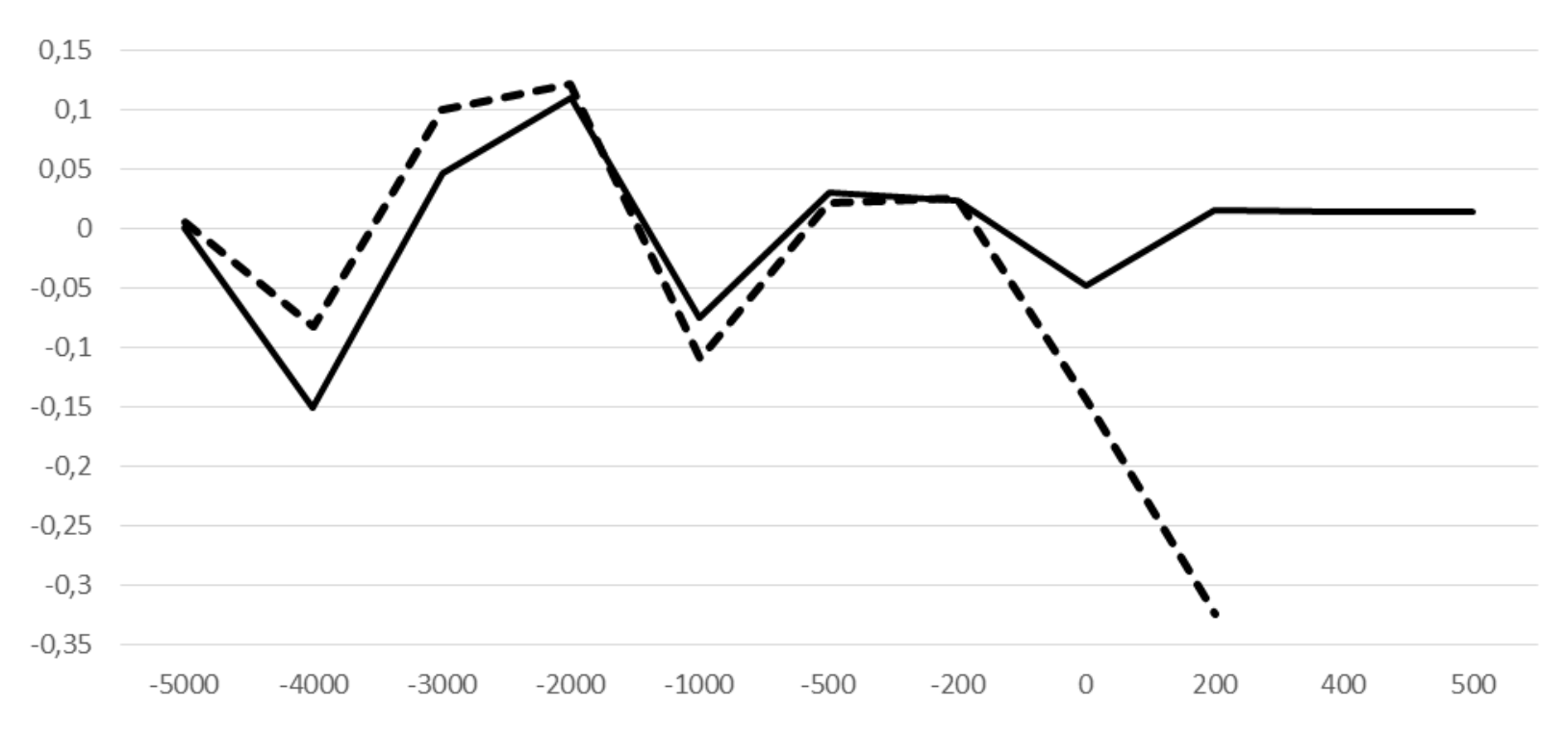

Рисунок 5. Отклонение оценок за даты с 5000 г. до н.э. по 500 г. н.э. от «гиперлогистической» (сплошная линия, $\mathbf{R}^{2}=0,9978$ ) и гиперболической (пунктирная линия, $\left.R^{2}=0,9912\right)$ кривых

Однако почему человечеству присущ гиперболический рост? Различные авторы называют следующие причины [Цирель 2008:255]:

- $\quad$ развитие технологий (С. Кузнец, Дж. Саймон, М. Кремер, А. Подлазов, С. Цирель, А. Коротаев, А. Малков и Д. Халтурина и др.);

- $\quad$ накопление знаний, парное информационное взаимодействие больших групп людей (С. Капица);

- гиперболический рост числа изобретений благодаря парному взаимодействию уже существующих (А. Фомин);

- построение гармонической сети (А. Молчанов);

- $\quad$ рост объёма информации (В. Анисимов) и др.

Первая из перечисленных и наиболее распространённая точка зрения объясняет развитие технологий ростом числа «изобретателей», которое полагается пропорциональным численности человечества (см., например, [Коротаев, Малков, Халтурина 2005a, 2025b; Коротаев 2006; Коротаев и др. 2010; Цирель 2008, 2014] и др.). Именно к ней относятся упомянутые выше парадоксы основного объяснения гиперболического закона [Цирель 2015]:

- всё или, по крайней мере, подавляющее большинство человечества должно было представлять собой единую систему по меньшей мере в течение 5 тыс. лет (крайние оценки - миллионы лет), так как изобретения должны были в течение относительно коротких сроков становиться известными большей части населения Земли;

- эффективность новаций и изобретений и доля изобретателей в составе человечества постоянны в течение тех же сроков; 
- в течение тех же сроков, независимо от скорости обмена информацией и её количества, от темпов внедрения изобретений в практику, изобретения дублировались в одной и той же мере;

- модель работает, несмотря на то, что фактически большая часть изобретений получена в отдельных, часто небольших, странах в особые эпохи (античная Греция, Суньский Китай, Италия эпохи Возрождения, Англия времён промышленной революции и др.), а огромные регионы мира изобретали очень мало;

- предположение, что само возникновение таких сообществ линейно связано с общим населением Земли, должно было бы привести к гораздо худшей аппроксимации роста населения Земли гиперболой, чем фактически наблюдалось;

- отсутствие влияния (или малое влияние) на рост населения Земли других важнейших обстоятельств: образования современной Мир-Системы в XVIII-XIX веках, изменений характера роста населения в западных странах в течение последних двух веков и др.

Относительно первого из этих замечаний можно сослаться на работу [Коротаев 2006], относящую создание Мир-Системы к гораздо более ранним срокам, связывая его с развитием не экономических, а информационных связей между различными регионами. В то время, когда технологии были сравнительно простыми, передача их от одного народа к другому не представляла большой сложности. К тому же историческое время текло тогда гораздо медленнее, чем сегодня, поэтому движение знаний и технологий от региона к региону в течение сотен и даже тысяч лет всё же укладывалось в необходимые для установления коллективного взаимодействия рамки.

Остальные пять парадоксов объяснения в той или иной степени снимаются, если пропорцию между численностью человечества и технологическим уровнем выводить не из числа изобретателей, а из числа потребителей, которые как раз и составляют всё население (с поправкой, может быть, только на его платёжеспособность). Впрочем, даже низкая платёжеспособность жителей, к примеру колониальных стран, не отменяла воздействия их численности на изобретательскую активность колонизаторов: ведь уже для покорения и поддержания колоний в покорности требовалось наличие технологического превосходства над ними.

Следует вспомнить хотя бы известную фразу Ф. Энгельса [1955-1974]: «Если у общества появляется техническая потребность, то это продвигает науку вперед больше, чем десяток университетов». Конечно, нельзя абсолютизировать - потребности в изобильной и хорошей еде, тёплой и лёгкой одежде, быстром транспорте были у людей всегда. Движущей силой они становились, когда появлялась реальная возможность создания соответствующих технологий. Таким образом, мы с другой стороны подошли к мысли, выраженной в работе [Коротаев, Малков, Халтурина 2005b: 14] следующим образом: «озарение изобретателя - это только флуктуация, во многом случайная мутация, которая затем проходит более суровый и объективный отбор, жестко связанный с текущим уровнем технологии. При этом интенсивность флуктуаций - число изобретений и (что не менее важно) попыток их внедрения, также является важным фактором наряду с технологическим уровнем». Остаётся добавить, что наличие потребностей, зависящее от количества потребителей, влияет и на число изобретений, и тем более на число попыток их внедрения. 
А.В. Подлазов [2015] предложил пойти дальше и провозгласил технологический императив, в соответствии с которым численность населения определяется размером технологической ниши - количеством людей, которые могут быть востребованы существующими технологиями ${ }^{4}$. Впрочем, поскольку технологическое развитие очень тесно взаимосвязано с ростом численности населения, неоднозначность выявления определяющего фактора неудивительна.

Другой подход представлен фундаментальными работами С.П. Капицы [1997; 1999], который на основании упомянутой выше модели гиперболического роста сформулировал демографический императив - утверждение о самодостаточности демографии в описании истории человечества. В работах Капицы несколько преувеличена точность соответствия построенной им модели реальному росту численности населения, кроме того его подход критикуют [Коротаев, Малков, Халтурина 2005b] за необоснованное обобщение эмпирической по сути зависимости. Однако вклад Капицы в развитие закона гиперболического роста трудно переоценить прежде всего потому, что им наиболее явно было указано на информационный характер процесса роста численности населения. В отличие от биологических популяций человечество способно накапливать информацию. Процесс роста информации является более фундаментальным, чем любые биологические, демографические или экономические явления. Он столь же закономерен, как процесс разбегания галактик, более того, он является обратной стороной основных космологических процессов. Коротаев и Малков [2009] убедительно показали, что подобный росту численности человечества гиперболический процесс наблюдается и в биологии как рост видового богатства экосистем, накапливающих генную информацию. Его можно наблюдать и в социальном развитии, и в техносфере, везде, где имеются способные накапливать информацию сложные системы.

Б.М. Долгоносов и В.И. Найденов [2006] предложили дополнить демографический императив информационным, в соответствии с которым глобальные демографические процессы подстраиваются под изменение объема накопленных человечеством знаний и знания выступают в качестве единственной движущей силы развития цивилизации. Действительно, мультипликативный характер роста информации, когда прорывной сдвиг порождает цепную реакцию новых подвижек, способствует гиперболическому увеличению количества информации в системах, имеющих возможность её накопления. Информационный императив не означает, что рост информации ни от чего более независим, но очень многие явления в сложных системах, таких как человечество, в основном определяются процессом накопления информации. Отметим, что накопление информации вполне может идти неравномерно, мультипликативность только усиливает случайные флуктуации. Однако при наличии множества параллельно идущих информационных процессов срабатывает закон больших чисел, сводящий неравномерность

\footnotetext{
${ }^{4}$ Подлазов оперирует понятием «жизнесберегающие технологии», понимая под ним любые знания и навыки, которые могут быть использованы для спасения человека и продления ему жизни. Однако не совсем понятно, каким образом из единого человеческого знания можно выделить только жизнесберегающую часть. Являлось ли, к примеру, изначально жизнесберегающим открытие Кюри или оно стало таковым лишь после того, как ядерные технологии начали применять в медицине? Возможно ли выделение жизнесберегающих религиозных догматов из общего религиозного контекста?
} 
к минимуму, поэтому с ходом времени степень соответствия роста численности гиперболическому закону возрастает.

Информационный императив позволяет дать ответ на первый парадокс Циреля: простота описания роста численности населения связана с определяющим влиянием фундаментальных процессов накопления информации, под которые подстраиваются все прочие процессы человеческого развития. А в сочетании со сделанным выше выводом, что коллективное взаимодействие имело место уже в глубокой древности, объясняется и третий парадокс: квадратичный характер роста определяется синергетическим взаимодействием информационных процессов во всей Мир-Системе. При этом продолжительные периоды, на протяжении которых заметного роста численности не было, соответствуют, вероятно, ослаблению взаимных связей в ходе расселения человека по планете.

Что же может дать понимание особенностей гиперболического роста для прогноза будущего? Во-первых, накопление информации может продолжаться практически бесконечно, с падением от этапа к этапу интенсивности этого процесса. Человек, возможно, уже в не слишком отдалённое время, должен будет передать функцию лидера развития машинам, но только от него самого будет зависеть степень его вовлеченности, а значит, и востребованности в информационных процессах. Никто не позволит развиваться человечеству исключительно как обществу потребления. Во-вторых, в ближайшее время, по мере завершения очередного этапа развития, можно ожидать вступления человечества в стадию бифуркаций, когда ход истории в большей, чем обычно, мере будет определяться случайными факторами. В частности, колоссальные массы молодёжи, выходящей на рынки труда в результате продолжающегося ещё в развивающихся странах демографического перехода, могут столкнуться вскоре со стремительным сужением этого рынка в ходе автоматизации и кибернетизации производства. Разрешение противоречия этих процессов в рамках существующей экономической парадигмы вряд ли возможно, а смена парадигмы может встретить сильнейшее противодействие действующих институтов.

\section{ЛИТЕРАТУРА}

Долгоносов Б.М., В.И. Найденов (2006). Информационная концепция динамики численности человечества. URL: http://www.iwp.ru/sites/files/iwp.ru/pub/18/2010-0205/EcolMod-2006, 198(3-4)375-386.pdf (дата обращения: 25.10.2015).

Капица С.П. (1997). Нелинейная динамика в анализе глобальных демографических проблем // Синергетика и прогнозы будущего / С.П. Капица, С.П. Курдюмов, Г.Г. Малинецкий. М.: Наука: 206-280.

Капица С.П. (1999). Сколько людей жило, живет и будет жить на земле, М.: Наука.

Коротаев А.В. (2006). Периодизация истории Мир-Системы и математические макромодели социально-исторических процессов // История и Математика. Проблемы периодизации исторических макропроцессов / Ред. Гринин Л.Е., Коротаев А.В., Малков С.Ю. М.: КомКнига/УРСС.

Коротаев А.В., А.С. Малков (2009). Гиперболический рост в природе и обществе. М.: Либроком. 
Коротаев А.В., А.С. Малков, Д.А. Халтурина (2005а). Законы истории: Математическое моделирование исторических макропроцессов. Демография. Экономика. Войны. М.: УРСС.

Коротаев А.В., А.С. Малков, Д.А. Халтурина (2005b). Математическая модель роста населения Земли, экономики, технологии и образования. М.: ИПМ им. М.В.Келдыша PAH.

Коротаев А.В., Д.А. Халтурина, А.С. Малков, Ю.В. Божевольнов, С.В. Кобзева, Ю.В. Зинькина (2010). Законы истории: Математическое моделирование и прогнозирование мирового и регионального развития. М.: Издательство ЛКИ.

Подлазов А.В. (2015). Технологический императив как основа теории глобального демографического процесса // Международная конференция «Демографическая история и демографическая теория: от описания к объяснению». М.: НИУ ВШЭ.

Цирель С.В. (2008). Заметки об историческом времени и путях исторической эволюции. Статья I// История и Математика: Модели и теории. М.: ЛКИ: 246-278.

Цирель С.В. (2014). О том, что будет после точки сингулярности // История и Математика: Аспекты демографических и социально-экономических процессов. Волгоград: Учитель.

Цирель С.В. (2015). О причинах гиперболического роста населения Земли и ухода от сингулярности // Международная конференция «Демографическая история и демографическая теория: от описания к объяснению». М.: НИУ ВШЭ

Энгельс Ф. (1955-1974). Письмо В. Боргиусу в Бреславль // Маркс К., Энгельс Ф. Сочинения. Издание 2-е. Т.39. М.: Издательство политической литературы: 174-177.

BirabenJ.-N. (1980). An Essay Concerning Mankind's Evolution // Population, Selected Papers. Vol. 4: 1-13.

Foerster von H., P. Mora, L. Amiot (1960). Doomsday: Friday, 13 November, A.D. 2026. At this date human population will approach infinity if it grows as it has grown in the last two millennia // Science. Vol.132. №1291-1295.

Hoerner S.J. von. (1975). Population Explosion and Interstellar Expansion // Journal of the British interplanetary Society. Vol.28: 691-712.

HYDE (History Database of the Global Environment 3.1) (2011). Netherlands Environmental Assessment Agency (PBL). URL:

http://themasites.pbl.nl/tridion/en/themasites/hyde/basicdrivingfactors/population/index2.html (дата обращения: 05.11.2015).

McEvedy C., R. Jones (1978). Atlas of World Population History // New York: Facts on File.

Postnikov E.B. (2015). Analytical properties of a three-compartmental dynamical demographic model // Physical Review. E 92012718.

UN Department of Economic and Social Affairs. Population Division (1999). The World at Six Billion.

UN Department of Economic and Social Affairs. Population Division (2013). Population of the entire world, yearly, 1950 - 2100 // World Population Prospects: The 2012 Revision.

US Census Bureau (2010). 


\title{
MYSTICISM AND TRUTH OF THE HYPERBOLIC LAW
}

\section{VALENTIN KONONOV}

VALENTIN KONONOV. INDEPENDENT EXPERT. E-MAIL: v_kononov@mail.ru.

DATE RECEIVED: December 2014.

\begin{abstract}
The analysis of findings from the works of scholars studying the law of hyperbolic growth of the world population shows that they are based almost exclusively on population statistics for the period from 1650 to 1970. In other periods population growth dynamics were governed by other laws. Moreover, the growth stages which could be identified with the attractors' flow were followed by stages of stagnation which could be defined as bifurcations.

The dominant understanding of the cause of hyperbolic growth as a consequence of technological development should also be rethought. The majority of the paradoxes of the law can be resolved if we admit that information processes are the driving force of human development.
\end{abstract}

Key words: population size, hyperbolic growth, attractor, bifurcation, demographic imperative, information imperative.

\section{REFERENCES}

Biraben J.-N. (1980). An Essay Concerning Mankind's Evolution // Population, Selected Papers. Vol. 4: 1-13.

Dolgonosov B.M., V.I. Naidyonov (2006). Informaczionnaya konczepcziya dinamiki chislennosti chelovechestva [Information concept of dynamics of number of mankind] URL: http://www.iwp.ru/sites/files/iwp.ru/pub/18/2010-02-05/EcolMod-2006,198(3-4)375-386.pdf (accessed: 25.10.2015).

Engels F. (1955-1974). V. Borgius letter in Breslavl // Marx K., Engels F.. Compositions. Edition 2 . T.39. M.: Izdatelstvo politicheskoj literatury: 174-177.

Foerster von H., P. Mora, L. Amiot (1960). Doomsday: Friday, 13 November, A.D. 2026. At this date human population will approach infinity if it grows as it has grown in the last two millennia // Science. Vol.132. №1291-1295.

Hoerner S. J. von. (1975). Population Explosion and Interstellar Expansion // Journal of the British interplanetary Society. Vol.28: 691-712.

HYDE (History Database of the Global Environment 3.1) (2011). Netherlands Environmental Assessment Agency (PBL). URL:

http://themasites.pbl.nl/tridion/en/themasites/hyde/basicdrivingfactors/population/index2.html (accessed: 05.11.2015).

Kapitza S.P. (1997). Nelinejnaya dinamika v analize global'nykh demograficheskikh problem // Sinergetika i prognozy budushhego [Nonlinear dynamics in the analysis of global demographic problems // Synergetrics and forecasts of the future] / S.P. Kapitza, S.P. Kurdyumov, G.G. Malinetzkyj. M.: Science: 206-280.

Kapitza S.P. (1999). Skol'ko lyudej zhilo, zhivet i budet zhit' nazemle [How many people lived, lives and there will live on the earth]. M.: Science.

Korotayev A.V. (2006). Periodizacziya istorii Mir-Sistemy i matematicheskie makromodeli social'no-istoricheskikh proczessov // Istoriya i Matematika. Problemy periodizaczii istoricheskikh makroproczessov [History periodization World System and mathematical macromodels of sociohistorical processes // History and Mathematics. Problems of a 
periodization of historical macroprocesses] / Edition Grinin L.E., Korotayev A.V., Malkov S.Y. M.: Komkniga/URSS.

Korotayev A.V., A.S. Malkov (2009). Giperbolicheskij rost v prirode i obshhestve [Hyperbolic growth in the nature and society]. M.: Librokom.

Korotayev A.V., A.S. Malkov, D.A. Halturina (2005b). Matematicheskaya model' rosta naseleniya Zemli, e'konomiki, tekhnologii i obrazovaniya [Mathematical model of growth of the population of Earth, economy, technology and education]. M.: Keldysh Institute of Applied Mathematics RAS.

Korotayev A.V., A.S. Malkov, D.A. Halturina (2005a). Zakony istorii: matematicheskoe modelirovanie istoricheskikh makroproczessov. Demografiya. E'konomika. Vojny [Laws of history: Mathematical modeling of historical macroprocesses. Demography. Economy. Wars]. M.: URSS.

Korotayev A.V., D.A. Halturina, A.S. Malkov, Y.V. Bozhevolnov, S.V. Kobzeva, Y.V. Zin'kina (2010). Zakonyistorii: matematicheskoe modelirovanie i prognozirovanie mirovogo i regional'nogo razvitiya [Laws of history: Mathematical modeling and forecasting of world and regional development]. M.: LKI publishing house.

McEvedy C., R. Jones (1978). Atlas of World Population History // New York: Facts on File.

Podlazov A.V. (2015). Tekhnologicheskij imperative kak osnova teorii global'nogo demograficheskogo proczessa [Technological imperative as a basis for the theory of global demographic process] // International conference "Demographic history and demographic theory: from description to explanation". M.: NRU HSE.

Postnikov E.B. (2015). Analytical properties of a three-compartmental dynamical demographic model // Physical Review. E 92012718.

Tsirel S.V. (2008). Zametki ob istoricheskom vremeni i putyakh istoricheskoj e'volyuczii [About historical time and ways of historical evolution]. Article I / History and Mathematics: Models and theories. M.: LKI: 246-278.

Tsirel S.V. (2014). O tom, chto budet posle tochki singulyarnosti [That will be after a singularity point] // History and Mathematics: Aspects of demographic and social and economic processes. Volgograd: Uchitel.

Tsirel S.V. (2015). O prichinakh giperbolicheskogo rosta naseleniya Zemli i ukhoda ot singulyarnosti [Of the causes of hyperbolic growth in world population and departure from singularity] // International conference "Demographic history and the demographic theory: from description to explanation". M.: NRU HSE.

UN Department of Economic and Social Affairs. Population Division (1999). The World at Six Billion.

UN Department of Economic and Social Affairs. Population Division (2013). Population of the entire world, yearly, 1950 - 2100 // World Population Prospects: The 2012 Revision.

US Census Bureau (2010). 